\title{
The Narrow Internal Auditory Canal with Triplication on the Left Side and with Duplication on the Right Side: Radiological Findings
}

\author{
Aydın Korkmaz ${ }^{1}$ \\ ${ }^{1}$ Rize State Hospital, Rize, Turkey \\ Received: 13 June 2020, Accepted: 17 June 2020, Published online: 30 August 2020 \\ (C) Ordu University Institute of Health Sciences, Turkey, 2020
}

\begin{abstract}
The constricted internal auditory canal with duplication or triplication of the temporal bone is a very rare anomaly with only 23 cases in 16 reports in the literature, and only one of them is a constricted triplicated internal auditory canal (IAC) in which contralateral IAC is normal. We present the case with the right-sided constricted duplicated IAC and the left-sided narrow triplicated internal auditory canal. Computerized tomography (CT) revealed that the internal auditory canals separated by a bony septum into two canals on the right lateral and into three canals on the left lateral. Magnetic resonance (MR) imaging showed bilateral aplasia of cochlear nerve.
\end{abstract}

Key words: Narrow duplicated, triplicated internal auditory canal, computed tomography, magnetic resonance imaging, congenital hearing loss

Suggested Citation: Korkmaz A. The Narrow Internal Auditory Canal with Triplication on the Left Side and with Duplication on the Right Side: Radiological Findings. Middle Black Sea Journal of Health Science, 2020; 6(2):266-271

\section{Address for correspondence/reprints:}

Aydın Korkmaz

Telephone number: +90 (535) 2921142

ORCID-ID 0000-0001-7283-2795

E-mail: draydinkorkmaz@hotmail.com

DOI: $10.19127 /$ mbsjohs. 752502

\section{Introduction}

In children with sensorineural hearing loss (SNHL), thanks to improvements of imaging technology and awareness in ear anomalies, the ratio of visible bony inner anomalies including abnormalities in the size and configuration of the cochlear and vestibular structure and in the size and shape of the internal auditory canal (IAC) and the vestibular aqueduct have increased to 30\% (McClay et al., 2002). One of these anomalies, narrow duplicated or triplicated IAC, is a very rare anomaly. We found 23 cases in 16 reports in Med-line search using the following terms: internal auditory canal, double, duplication, duplicated, triplication, triplicated (Curtin et al., 1986; Coelho et al., 2010). Only one of 24 cases were triplicated internal auditory canal in which contralateral IAC was normal (Lee at al., 2009).

Although high resolution computed tomography (HRCT) is used to evaluate separated, accessory bony canals in duplicated or triplicated narrow IAC, it has little place in the evaluate of ICA's neural elements. 
Magnetic resonance (MR) imaging gives detailed anatomical information about vestibulocochlear and facial nerves of the internal auditory canal. Herein, HRCT and MR imaging findings in a child who had the left-sided narrow triplicated IAC and the rightsided narrow duplicated IAC.

\section{Case}

A 5-year-old girl with complaint of hearing loss was followed by ear, nose, and throat department. Her complaint was recognized when she was baby. Her perinatal history was normal. Her ear, nose and throat examination were normal. An audiogram revealed bilateral profound SNHL. She had normal facial function. Sensorineural hearing loss information was not detected in her family. She referred to radiology department for temporal computed tomography (CT) imaging. CT examination was performed with a 64-dedector CT scanner (Aquilion 64, Toshiba, Tokyo Japan) and three-dimensional reformatted $\mathrm{CT}$ images was obtained. CT images revealed that the internal auditory canals separated by a bony septum into three narrow canals (anterosuperior, posterosuperior and inferior canal) on the left side and two narrow canals (superior and inferior canal) on the right side. Due to the bony septa between two canals was incomplete, the anterosuperior and the posterosuperior canals fused at origin and at lateral end on the left side. The anterosuperior canal on the left lateral and the superior canal on the right lateral continued with a wide connection in the facial canal. The posterosuperior canal, the inferior canal on the left lateral and inferior canal on the right lateral ended a connection to the vestibule. There were a very narrow connections between the inferior canals and the cochlea's (Figure.1). Bilateral vestibules were larger than normal. The facial nerve pathways (labyrinthine segment, geniculate ganglion, tympanic and mastoid segments) were normal on both sides. Additional middle or external inner ear anomalies were not found. MRI examination performed by a $1.5 \mathrm{~T}$ MRI scanner (Vision plus, Siemens, Germany )included following protocols: T1-weighted SE axial sequence (TR/TE: 400/25, $3 \mathrm{~mm}$ slice thickness), T2-weighted SE axial sequence (TR/TE: 2000/635, $3 \mathrm{~mm}$ slice thickness), a three dimensional constructive interference in the steady state (3D FT-CISS) (TR/TE: $12.25 / 5.9$, 1mm slice thickness). Sagittal, parasagittal and coronal reformatted MR images were obtained. MRI showed two nerve in both cerebellopontine angles. The anterosuperior canal and posterosuperior canal on the left lateral and the superior canal on the right lateral contained nerve fibers thought to be facial nerve and vestibular nerve. No nerve fibers were delineated in the inferior canals ending to cochlea (Figure 2).

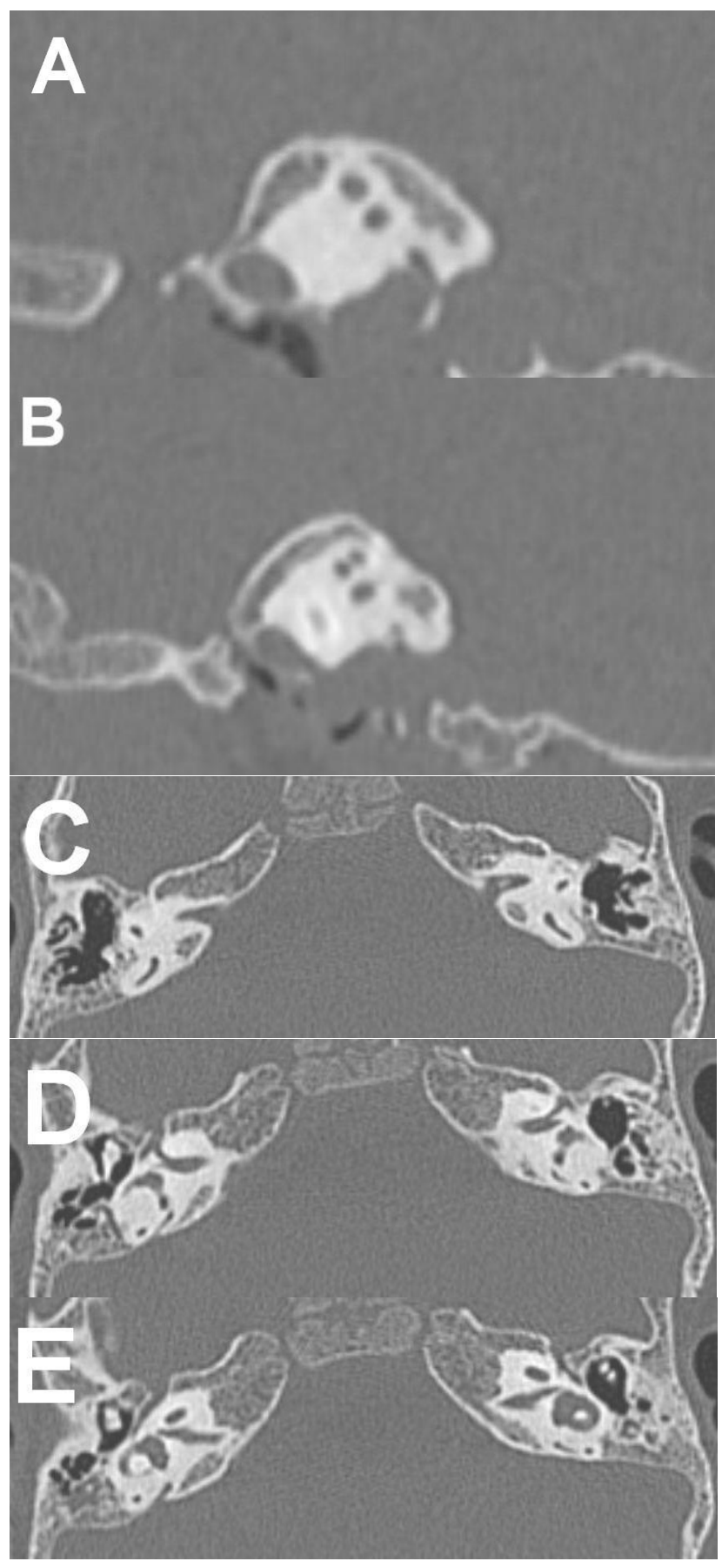




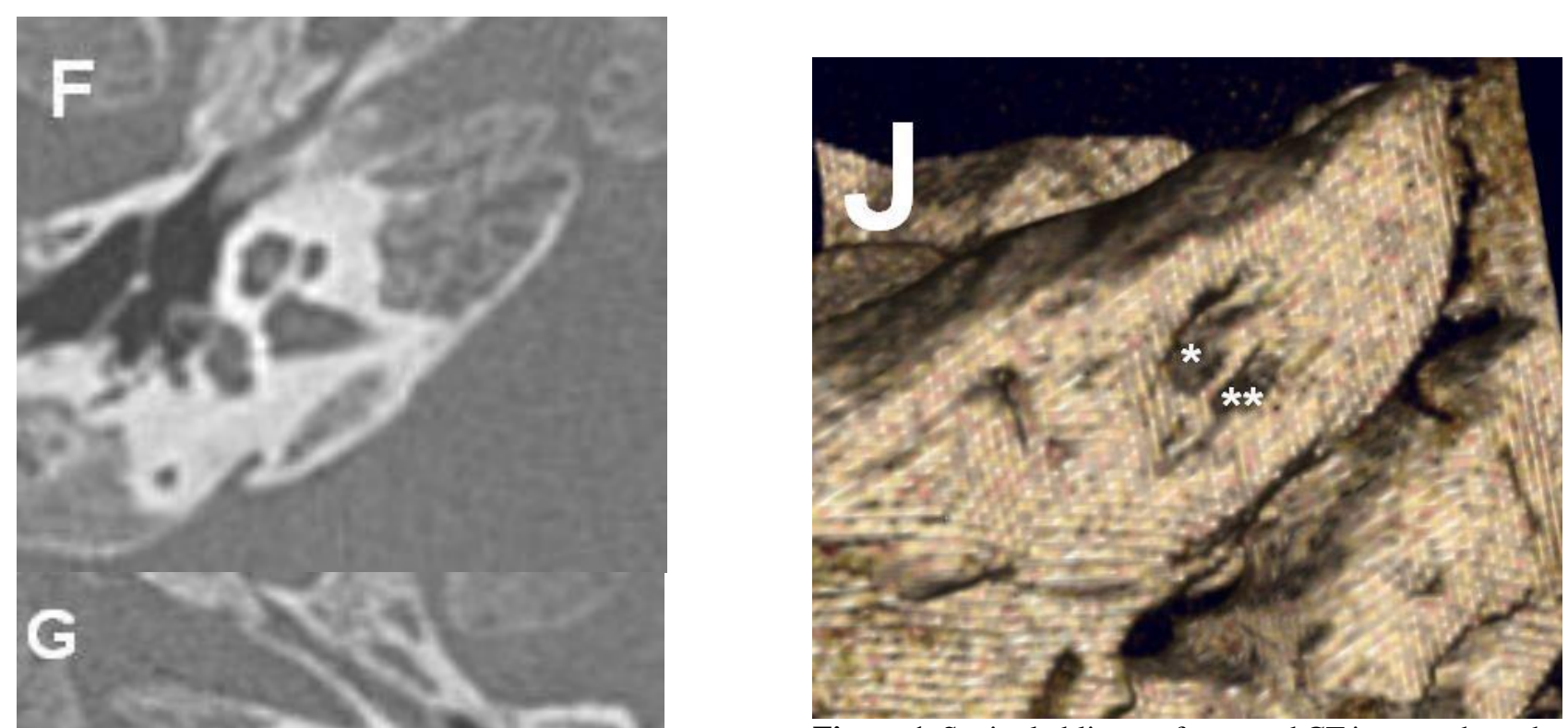

Figure 1. Sagittal oblique reformatted CT images show the IACs divided to two parts (superior and inferior) on the right side (A) and three parts (anterosuperior, posterosuperior, and inferior) on the left side (B) by bony septas. Consecutive axial HRCT images show the superior part of the duplicated IAC on the right lateral and the anterosuperior and the posterosuperior canals of the triplicated IAC on the left lateral. On the right lateral, the superior canal ends in a connection both in labyrinthine segment of the facial nerve canal and in vestibule. On the left side, the anterosuperior canal continues as facial nerve canal while the posterosuperior canal ends connection in vestibule. Bilateral vestibules are larger than normal, which is more prominent on the right lateral $(\mathrm{C}-\mathrm{E})$. The inferior canals coursing to the cochlea's are seen $(F, G) .3$ $\mathrm{D}$ reformatted image of lateral aspect of the right temporal bone displays two separate orifices belong to superior canal (single asterisks) and inferior canal (double asterisks) $(\mathrm{H})$. Anterosuperior and posterosuperior canals which have common orifice are divided by bony septa (arrow) at a few millimeters from the orifice (I). The common orifice of the superior canals (single asterisks) and the orifice of inferior canal (double asterisks) are seen (J). 

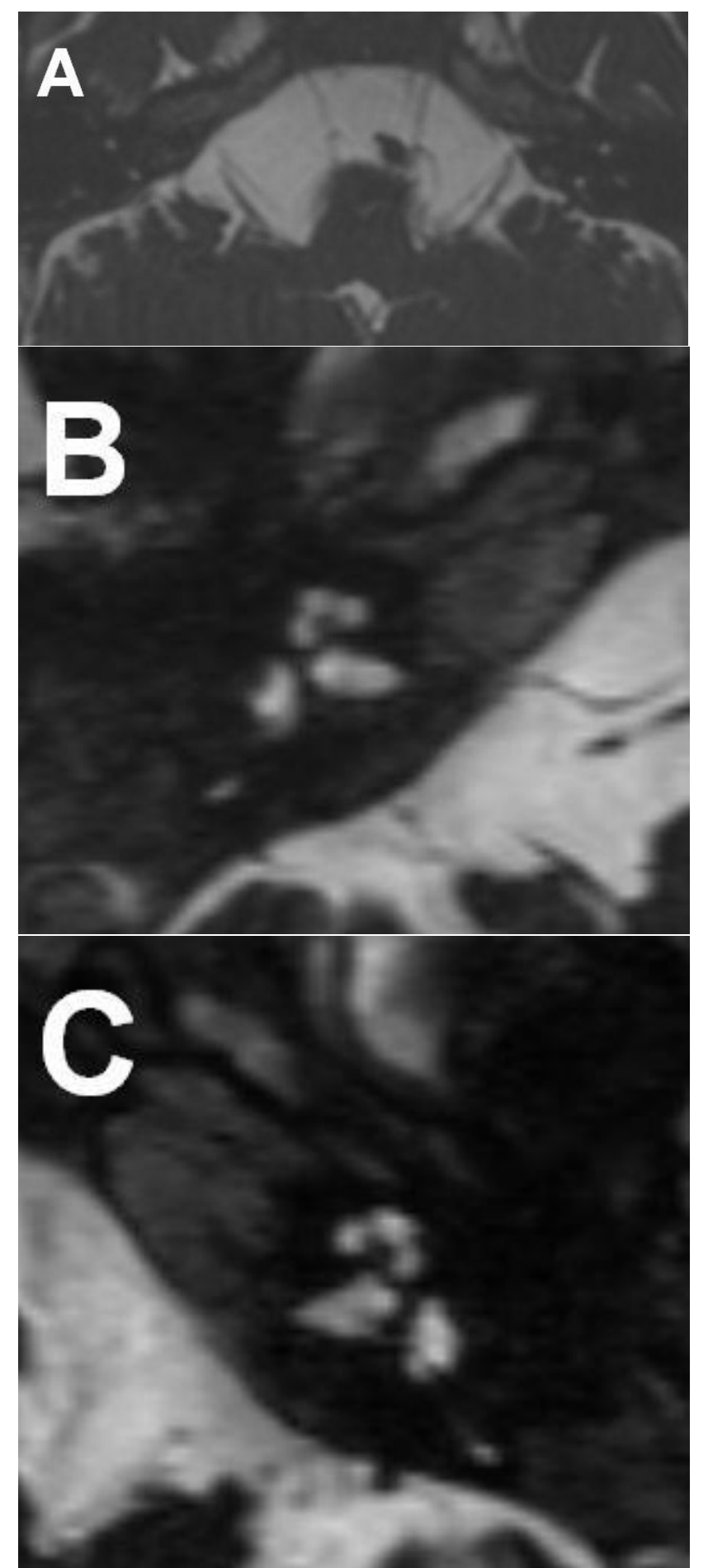

Figure 2. Axial 3D CISS MR image two nerve, which may be a facial nerve and a vestibular nerve are seen at the both cerebellopontine angle (A). The inferior canals in both sides are empty without nerve fibers (B, C).

\section{Discussion}

If the diameter of IAC, which is normally between 2 to $8 \mathrm{~mm}$ (mean $4 \mathrm{~mm}$ ), is less than $2 \mathrm{~mm}$, this condition is referred as "narrow IAC" (Demir et al., 2005; Lee et al., 2009). This anomaly has high association with the temporal bone's some other abnormalities of and various systemic congenital anomalies, cardiac, renal, skeletal, and intestinal malformations. (Demir et al., 2005; Wang et al., 2010). Internal auditory canal anomalies can be components of some syndromes as seen unilateral narrow duplicated case with Klippeil-Feil presented by Demir et al (Demir et al., 2005). In case presented by Goktas et al, this malformation was associated walking and balance disturbances, and ocular hypertelorism. However, this malformation may exist without other systemic anomalies (Vilain et al., 1999; Cho et al., 2000). The associated inner ear anomalies including Mondini dysplasia, vestibulocochlear dysplasia, semicircular canal dysplasia and enlarged vestibular aqueduct were previously reported (Ferreira et al., 2003; Baik et al., 2008; Coelho., 2010). In the literature were three cases in that narrow-duplicated IAC were associated with external ear anomaly (Casselman et al.,1997; Demir et al., 2005; Kono et al., 2009).

Embryologically, the labyrinthine is derived from the otic placode that later transforms the otic vesicle from which the audio vestibular structures originate. On the 29th days of gestation, the vestibulocochlear nerve begins to develop, and its growth is thought to be induced by the embryonic labyrinth by chemotactic mechanism. During fifth and sixth months of gestation, the mesoderm surrounding seventh and eighth nerves forms bony IAC by chondrification and by ossification (Ferreira et al., 2003). Two hypotheses have been suggested to explain the relation between narrow IAC and SNHL: either primary aplasia-hypoplasia of the vestibulocochlear nerve negatively influencing normal development of the IAC or primary bone defect causing growth failure of the vestibulocochlear nerve (Ferreira et al., 2003; Demir et al., 2005; Baik et al., 2008; Goktas et al., 2008; Lee et al., 2009). Although facial weakness associated with duplicated IAC was only reported in report by Curtin et al (Curtin et al., 1986), given the fact that normal function of facial nerve in most cases with duplicated or triplicated narrow IAC cannot be explained by second theory, the possibility of this theory is low (Ferreira et al., 2003; Lee et al., 2009). If there is a separate canal for the intracanalicular segment of the facial nerve when the IAC is atretic or stenotic, may it be defined as duplication of the IAC? In the literature, such cases were not named as duplication, as occurred in the report by Westerhof et al. (2001).

While there were only 7 cases about narrow duplicated IAC in the literature until 2000, after then 
17 cases (with adding our case) has been reported (Curtin et al., 1986; Coelho et al., 2010). This may attributable to developments in imaging technology during the past decade. The HRCT is the best choice to evaluate the bony structures of the IAC and temporal bone with high sensitivity and spasticity (Linsheng et al., 2019) but It has little place in the evaluate of ICA's neural elements. Evaluation of the cochlear nerve is critical for selecting patients for cochlear implantation in patient with narrow IAC, because the patients who don't have cochlear nerves may not respond to the electric stimulation of cochlear implantation (Kono et al., 2009). Therefore, the HRCT imaging is not appropriate for rule out the risk of aplasia or hypoplasia of the vestibulocochlear nerve and MR imaging should be performed to detect of presence or absence of that neural structures in IAC (Vilain et al., 1999). The extensive anatomical data on vestibulocochlear and facial nerve have been gathered by using high-resolution gradient-echo imaging consisting of 3D Fourier transformationconstructive interference in the steady state (3D FTCISS), 3D magnetization prepared rapid gradient echo (MP-RAGE), 3D balanced fast field echo (BFFE), and 3D DRIVE sequences (Goktas et al., 2008). The data are collected via these sequences which are three-dimensional and submillimeter at spatial resolution, besides they are optimal to evaluate the neural structures like vestibulocochlear and facial nerves which are less than $1 \mathrm{~mm}$ in diameter (Goktas et al., 2008). By using sagittal and parasagittal reconstruction for evaluating neural structures in IAC's, a 3D Fourier transformation-constructive interference in the steady state (3D FT-CISS) was used in this case.

\section{Conclusion}

In conclusion, the constricted internal auditory canal with duplication or triplication, usually associated with sensorineural hearing loss should be examined radiologically with both HRCT and MR imaging. Exhibition of absence or presence of cochlear nerve in narrow IAC by MR imaging is essential because it may affect the planning of treatment in cochlear implant candidates.
Ethics Committee Approval: The consent form was taken for the case report.

Peer-review: Externally peer-reviewed.

Author Contributions: Concept - A.K.; Design- A.K.; Supervision- A.K.; Materials- A.K.; Data Collection and/or Processing- A.K.; Analysis and/or Interpretation-A.K.; Literature Review- A.K.; WritingA.K.; Critical Review- A.K.

Conflict of Interest: No conflict of interest was declared by the author.

Financial Disclosure: The author declared that this study hasn't received no financial support.

\section{References}

Baik HW, Yu H, Kim KS, Kim GH. A narrow internal auditory canal with duplication in a patient with congenital sensorineural hearing loss. Korean J Radiol. 2008; 9(suppl):S22-25.

Casselman JW, Offeciers FE, Govaerts PJ, Kuhweide R, Geldof H, Somers T, D'Hont G. Aplasia and hypoplasia of the vestibulocochlear nerve: diagnosis with MR imaging. Radiology. 1997; 202:773-781.

Cho YS, Na DG, Jung JY, Hong SH. J Narrow internal auditory canal syndrome: parasaggital reconstruction. Laryngol Otol. 2000; 114:392394.

Coelho LO, Ono SE, Neto AC, Polanski JF, Buschle M. Bilateral narrow duplication of the internal auditory canal. J Laryngol Otol. 2010; 4:10031006.

Curtin H, May M. Double internal auditory canal associated with progressive facial weakness. Am J Otol. 1986; 7:275-281.

Demir OI, Cakmakci H, Erdag TK, Men S. Narrow duplicated internal auditory canal: radiological findings and review of the literature. Pediatr Radiol. 2005; 35:1220-1223.

Ferreira T, Shayestehfar B, Lufkin R. Narrow, duplicated internal auditory canal. Neuroradiology. 2003; 45:308-310.

Goktas Bakar T, Karadag D, Calisir C, Adapinar B. Bilateral narrow duplicated internal auditory canal. Eur Arch Otorhinolaryngol. 2008; 265:9991001.

Guirado CR. Malformations of the inner auditory canal. Rev Laryngol Otol Rhinol 1992; 113:419421. 
Kesser BW, Raghavan P, Mukherjee S, Carfrae M, Essig G, Hashisaki GT. Duplication of the internal auditory canal: radiographic imaging case of the month. Otol Neurotol. 2010; 31:1352-1353.

Kono T, Kuwashima S, Arakawa H, Yamazaki E, Kitajima K, Ejima Y, Ishikawa T, Hashimoto T, Kaji Y. Narrow duplicated internal auditory canal: a rare inner ear malformation with sensorineural hearing loss. Arch Otolaryngol Head Neck Surg. 2009; 135:1048-1051.

Lee SY, Cha SH, Jeon MH, Bae IH, Han GS, Kim SJ, Park KS. Narrow duplicated or triplicated internal auditory canal (3 cases and review of literature): can we regard the separated narrow internal auditory canal as the presence of vestibulocochlear nerve fibers? J Comput Assist Tomogr. 2009; 33:565-570.

Linsheng W, Lihong Z, Xian L, Xiang G. Duplicated internal auditory canal: High-Resolition CT and MRI findings. K J Radiology. 2019; 823-829

McClay JE, Tandy R, Grundfast K, Choi S, Vezina G, Zalzal G, Willner A. Major and minor temporal bone abnormalities in children with and without congenital sensorineural hearing loss. Arch Otolaryngol Head Neck Surg. 2002; 128:664-671.

Vilain J, Pigeolet Y, Casselman JW. Narrow and vacant internal auditory canal. Acta Otorhinolaryngol Belg. 1999; 53:67-71.

Wang LS, Zhang LH, Sun XH, Yang YY, Chen YQ, Li X, Sheng HQ, Sun ZG. [Imaging features of duplication of the internal auditory canal]. Zhonghua Er Bi Yan Hou Tou Jing Wai Ke Za Zhi. 2010; 45:481-485.

Weisman JL, Arriaga M, Curtin HD, Hirsch B. Duplication anomaly of the internal auditory canal. Am J Neuroradiol 1991; 12:867-869.

Weon YC, Kim JH, Choi SK, Koo JW. Bilateral duplication of the internal auditory canal.Pediatr Radiol. 2007; 37:1047-1049.

Westerhof JP, Rademaker J, Weber BP, Becker H.J Congenital malformations of the inner ear and the vestibulocochlear nerve in children with sensorineural hearing loss: evaluation with $\mathrm{CT}$ and MRI. Comput Assist Tomogr. 2001; 25:719-726. 